\title{
CORRELATION BETWEEN NURSING CARE QUALITY AND PATIENT SATISFACTION LEVEL IN RUMAH SAKIT JIH YOGYAKARTA
}

\author{
Aan Devianto ${ }^{1}$, Catur Budi Susilo², Lina Eka Wat ${ }^{3}$ \\ 1,3 Prodi S1 IImu Keperawatan STIKES Guna Bangsa Yogyakarta \\ ${ }^{2}$ Poltekes Kemenkes Yogyakarta
}

\begin{abstract}
Background: Nursing care quality as an indicator for the quality of health care is one of the determining factors for health care institutions image. Nurse is the profession with the highest number, at the front line and closest to the suffering and illness of patients and families. One of the indicators of nursing care quality is whether the nurses give satisfying services to patients or not.
\end{abstract}

Objective: The goal of this research is to find out correlation between nursing care quality and patient satisfaction level in Rumah Sakit JIH Yogyakarta.

Methodology: The type of this research is descriptive analytic non experimental; which used cross sectional approach. The technique for collecting sample was proportionate stratified random sampling; with 100 outpatients in Rumah Sakit $\mathrm{JIH}$ Yogyakarta as the respondents. The collecting sample used questionnaire while the analyzing used Rank Spearman Correlation.

Result: The results of this research are (1) nursing care quality in Rumah Sakit JIH Yogyakarta are $45 \%$ good and $54 \%$ good enough, (2) patient satisfaction level in Rumah Sakit $\mathrm{JIH}$ Yogyakarta are $87 \%$ moderate level and $12 \%$ high level. The result for Rank Spearman is $r$ account of 0,440 ; and it has probability of $0,000(0,000<0,05)$. Hence, there is correlation between nursing care quality and patient satisfaction level in Rumah Sakit $\mathrm{JIH}$ Yogyakarta with the result in moderate level.

Conclusion: the correlation between nursing care quality with outpatient satisfaction level in Rumah Sakit JIH Yogyakarta is on moderate level.

Keywords : Nursing care quality, Patient satisfaction level

\section{PENDAHULUAN}

Indonesia Sehat 2025 diharapkan masyarakat memiliki kemampuan menjangkau pelayanan kesehatan yang bermutu dan memperoleh jaminan kesehatan.Pelayanan kesehatan yang bermutu yang dimaksud adalah pelayanan kesehatan termasuk pelayanan keperawatan dalam keadaan darurat dan bencana, pelayanan kesehatan yang memenuhi kebutuhan masyarakat serta diselenggarakan sesuai dengan standar dan etika profesi ${ }^{1}$.

Mutu pelayanan keperawatan adalah derajat kesempurnaan pelayanan keperawatan yang dapat memuaskan setiap pemakai jasa pelayanan keperawatan sesuai dengan tingkat kepuasan rata-rata penduduk, serta yang menyelenggarakannya sesuai dengan standar dan kode etik profesi yang telah ditetapkan dengan menyesuaikan potensi sumber daya yang tersedia secara wajar, 
efisien dan efektif serta diberikan secara aman dan memuaskan sesuai dengan norma, etika, hukum, dan social budaya dan memperhatikan keterbatasan dan kemampuan pemerintah dan masyarakat konsumen ${ }^{2}$. Tingkat kepuasan pelanggan sangat tergantung pada mutu suatu produk. Makin sempurna kepuasan tersebut, makin baik pula mutu pelayanan keperawatan ${ }^{3}$. Kepuasan seseorang bersifat subyektif, tergantung dari latar belakang yang dimiliki dan dapat saja memiliki tingkat kepuasan berbeda untuk pelayanan keperawatan yang sama.

Terdapat lima dimensi mutu yang yaitu sebagai berikut:Tangibles (Dimensi Bukti Nyata), Reliability (Dimensi Kehandalan), Responsiveness (Dimensi Ketanggapan), Assurance (Dimensi Jaminan), Emphaty (Dimensi Perhatian) ${ }^{4}$. Rumah Sakit JIH dituntut untuk selalu menjaga kepercayaan konsumen dengan meningkatkan kualitas pelayanan agar kepuasan konsumennya meningkat.

Berdasarkan Laporan Pemantauan Sasaran mutu untuk mengetahui kepuasan pelayanan rawat jalan dari Januari Desember 2014 dan hasil dari studi pendahuluan wawancara yang dilakukan oleh peneliti pada bulan mei 2015. Didapatkan angket kepuasan pelayanan rawat jalan pada Januari (88\%), Februari $(87,8 \%)$, Maret $(85 \%)$, April (89\%), Mei $(92 \%)$, Juni $(90 \%)$, Juli (86\%), Agustus (94\%), September (93,4\%), Oktober $(92,47 \%)$, November $(82,01 \%)$, Desember $(76,12 \%)$ standart tarjet rumah sakit untuk meningkatkan kepuasan pelayanan rawat jalan adalah $85 \%$. Dengan wawancara pada 20 pasien yang menjalankan rawat jalan di poliklinik Berdasarkan hasil dari studi pendahuluan yang dilakukan oleh peneliti pada Juni 2015 di Poliklinik rawat jalan RS JIH dengan wawancara pada 20 pasien yang menjalankan rawat jalan di Poliklinik rawat jalan $\mathrm{RS} \mathrm{JIH}$ didapatkan hasil bahwa 10 orang mengatakan perawat kurang komunikasif menjelaskan tindakan keperawatan, 5 orang mengatakan keterampilan pasang infuse tidak sekali pasang bisa, 3 orang mengatakan perawat nampak buru buru saat menensi, 2 orang mengatakan saat pasien datang mau bertanya, perawat tidak ada di nurse stasion.
Berikut data kunjungan pasien rawat jalan atau poliklinik di Rumah Sakit JIH Yogyakarta selama 1 tahun yaitu periode Januari-Desember 2014 sebagai berikut: Januari 10.142, Februari 9.229, Maret 10.020, April 9.869, Mei 10.279, Juni 8.779, Juli 6.941, Agustus 8.950, September 9.828, Oktober 9.074, November 8.981, Desember 10.610 total 112.720 .

Berdasarkan hasil studi pendahuluan, maka peneliti tertarik untuk meneliti "Hubungan Kualitas Mutu Pelayanan Keperawatan Dengan Tingkat Kepuasan Pasien Rawat Jalan Rumah Sakit JIH Yogyakarta", karena diharapkan akan berdampak pada peningkatan kualitas mutu pelayanan keperawatan dengan tingakat kepuasaan pasien. Sehingga kepercayaan pasien akan pelayanan keperawatan di Rumah Sakit $\mathrm{JIH}$ akan semakin meningkat.

\section{METODE PENELITIAN}

Jenis penelitian ini adalah deskriptif analitik non eksperimental dengan menggunakan pendekatan CrossSectional yaitu pengambilan dan pengumpulan data variabel bebas dalam penelitian ini adalah kualitas mutu pelayanan keperawatan yang terdiri dari bukti nyata (tangibes), kehandalan (reliability), ketanggapan (responsiveness), jaminan (assurance), empati (empathy) dengan Variabel terikat dalam penelitian ini adalah yaitu tingkat kepuasan pasien yang terdiri: sikap, pengetahuan, ketrampilan, fasilitas dan prosedur. Penelitian ini dilakukan di unit rawat jalan di Rumah Sakit JIH Yogyakarta dan dilaksanakan pada bulan DesemberJanuari 2016. Populasi dalam penelitian ini adalah pasien rawat jalan di Rumah Sakit JIH Yogyakarta, yang berjumlah 100 pasien. Teknik pengambilan sampel dengan tehnik Proportionate stratified randam sampling yaitu suatu cara pengambilan sampel yang digunakan bila populasi mempunyai anggota/unsur yang tidak homogen dan berstrata secara proposional $^{5}$. Jenis data dalam penelitian ini adalah Data primer yaitu data yang diperoleh langsung dari subyek penelitian. Instrumen yang digunakan untuk 
pengumpulan data dalam penelitian ini adalah kuesioner. Kuesioner mutu pelayanan keperawatan dengan 23 pernyataan dengan alternatif jawaban yang digunakan menggunakan deskripsi penetapan skala dengan kriteria sebagai berikut (4) sangat baik, (3) baik, (2) tidak baik, (1) sangat tidak baik, jawaban menggunakan skala Likert't. Kuesioner tentang kepuasan dengan 24 pertanyaan menggunakan skala Likert dengan deskripsi: sangat puas, puas, tidak puas, sangat tidak puas. Skala Likert dapat digunakan untuk mengukur sikap, pendapat dan persepsi seseorang atau sekelompok seseorang ${ }^{5}$. Kuesioner disusun oleh peneliti, peneliti juga melakukan pengembangan dan modifikasi dari kuesioner ${ }^{7}$, pengembangan dan modifikasi kuesioner yang dilakukan oleh peneliti sesuai dengan literatur ${ }^{8}$. Penelitian ini telah dilakukan uji validitas dengan mengunakan rumus Product Moment dengan menggunakan alat bantu sistem komputer dengan program SPSS windows versi 13.00 dan uji reliabilitas menggunakan rumus cronbach alpha. Hasilnya dari pernyataan kuesioner kepuasan pasien menunjukkan bahwa 24 peryataan valid dan untuk pertanyaan kuesioner kualitas mutu pelayanan keperwatan tidak diujikan karena sudah baku$^{6}$. Analisa data mengunakan analisis univariat dan analisis bivariat dengan mengunakan program SPSS windows versi 13.00. Analisis Univariat dilakukan bertujuan untuk menghasilkan presentase dari setiap variable, baik variable bebas (mutu pelayanan keperawatan) maupun variable terikat (kepuasan pasien).Analisis bivariat dilakukan untuk menguji hipotesis dan menjawab rumusan masalah yang diajukan dalam penelitian ini dengan menggunakan skala ordinal, kemudian mencari hubungan antara kepuasan pasien terhadap mutu pelayanan perawat menggunakan korelasi Spearmen Rank.

\section{HASIL DAN PEMBAHASAN}

\section{Gambaran Umum Lokasi Penelitian}

Rumah Sakit "JIH" pada awalnya bernama Jogja International Hospital, berada dibawah pengelolaan PT Unisia Medika Farma (PT UMF).Jogja
International Hospital mulai operasional pada tanggal 31 Maret 2007 grand opening Jogja International Hospital. Tanggal 1 Agustus 2010 nama Jogja International Hospital diganti menjadi RUMAH SAKIT "JIH". Tempat ini tersedia 200 tempat tidur inap.Jumlah Dokter 72 dokter. Rumah Sakit JIH mempunyai pelayanan rawat jalan gedung lama (Gedung A) meliputi Poli Utara (Poli Umum, Poli Mata, Poli Gigi, Poli Penyakit Internist, Poli Kulit Kelamin, Poli Jiwa, Poli Gizi, Poli Psikolog). Poli Timur (Poli Kebidanan dan Kandungan, Poli Anak) dan kelancaran transportasi medik ditunjang oleh pneumatic tube system.

Pada tanggal 2 November 2015 Rumah Sakit JIH melakukan soft opening gedung baru (Gedung B) dengan fasilitas yang dioperasikan lantai 1 meliputi Poli Barat (Poli Bedah, Poli Syaraf, Poli THT), Poli Utara (Poli Jantung dan Pembuluh Darah, Poli Paru, Poli Internist.

\section{Karakteristik Responden}

Tabel 1. Karakteristik Pasien Gender, Umur, Pendidikan dan Pekerjaan di Rawat Jalan Rumah Sakit JIH

\begin{tabular}{lcc}
\hline \multicolumn{1}{c}{ Karakteristik } & $\mathbf{n}$ & $\%$ \\
\hline Jenis kelamin & & \\
\hline Pria & 49 & 49 \\
Wanita & 51 & 51 \\
\hline Usia & & \\
\hline $17-21$ tahun & 8 & 8 \\
$21-40$ tahun & 44 & 44 \\
$40-60$ tahun & 37 & 37 \\
60 sd meninggal & 11 & 11 \\
\hline Pendidikan & & \\
\hline SLTA & 1 & 1 \\
S1 & 62 & 62 \\
S2 & 37 & 37 \\
\hline Pekerjaan & & \\
\hline PNS & 4 & 4 \\
Pensiun & 5 & 5 \\
Mahasiswa & 13 & 13 \\
Wiraswasta & 14 & 14 \\
IRT & 19 & 19 \\
Swasta & 45 & 45 \\
\hline$\quad$ Total & $\mathbf{1 0 0}$ & $\mathbf{1 0 0}$ \\
\hline
\end{tabular}

Sumber : Data primer diolah, 2016

Berdasarkan tabel 1. menunjukkan bahwa pasien rawat jalan rumah sakit 
JIH Yogyakarta data pria sebesar $49 \%$,dan wanita sebesar $51 \%$. Kategori umur menunjukkan bahwa pasien remaja sebesar $8 \%$, dewasa sebesar $44 \%$, setengah baya sebesar $37 \%$, dan tua sebesar $11 \%$. Hasil prosentase kategori pendidikan menunjukkan S1 sebesar $62 \%$, S2 sebesar $37 \%$ dan untuk kategori pekerjaan swasta sebesar $45 \%$, IRT sebesar $19 \%$, wiraswasta sebesar $14 \%$.

\section{a. Univariat}

Tabel 2.Kualitas Mutu Pelayanan Keperawatan Pasien Rawat Jalan Rumah Sakit JIH Yogyakarta

\begin{tabular}{lccc}
\hline Mutu Pelayanan & Kategori & $\mathbf{n}$ & $\mathbf{( \% )}$ \\
\hline Mutu Pelayanan & Baik & 45 & 45 \\
& Cukup & 54 & 54 \\
& Kurang & 1 & 1 \\
\hline & Total & $\mathbf{1 0 0}$ & $\mathbf{1 0 0}$ \\
\hline
\end{tabular}

Sumber : Data primer, 2016

Dari tabel 2. tersebut di atas, diperoleh hasil sebesar $45 \%$ mutu pelayanan rawat jalan di rumah sakit JIH termasuk dalam kategori baik dan 54\% kategori cukup.

\section{Tabel 3.Dimensi Kualitas Mutu Pelayanan KeperawatanPasien Rawat Jalan Rumah Sakit JIH Yogyakarta}

\begin{tabular}{|c|c|c|c|}
\hline \multirow{5}{*}{$\frac{\text { No }}{1 .}$} & Dimensi & $\mathbf{n}$ & $(\%)$ \\
\hline & $\begin{array}{l}\text { Tangible } \\
\text { (Dimensi bukti nyata) }\end{array}$ & & \\
\hline & Baik & 47 & 47 \\
\hline & Cukup & 52 & 52 \\
\hline & Kurang & 1 & 1 \\
\hline \multirow[t]{4}{*}{2.} & $\begin{array}{l}\text { Reliability } \\
\text { (Dimensi Kehandalan) }\end{array}$ & & \\
\hline & Baik & 13 & 13 \\
\hline & Cukup & 86 & 86 \\
\hline & Kurang & 1 & 1 \\
\hline \multirow[t]{4}{*}{3.} & $\begin{array}{l}\text { Responsiveness } \\
\text { (Dimensi Ketanggapan) }\end{array}$ & & \\
\hline & Baik & 0 & 0 \\
\hline & Cukup & 100 & 100 \\
\hline & Kurang & 0 & 0 \\
\hline
\end{tabular}

\begin{tabular}{llcc} 
No & \multicolumn{1}{c}{ Dimensi } & n & (\%) \\
\hline 4. & Assurance & & \\
& (Dimensi Jaminan) & & \\
& Baik & 0 & 0 \\
& Cukup & 99 & 99 \\
& Kurang & 1 & 1 \\
& Empathy & & \\
& (Dimensi Perhatian) & & \\
& Baik & 1 & 1 \\
& Cukup & 98 & 98 \\
& Kurang & 1 & 1 \\
& $\quad$ Total & $\mathbf{1 0 0}$ & $\mathbf{1 0 0}$ \\
& & & \\
& &
\end{tabular}

Sumber : Data primer, 2016

Pada dimensi bukti nyata (tangible) diperoleh hasil $47 \%$ termasuk kategori baik, sedangkan 52\%cukup. Dimensi kehandalan (reliability) diperoleh hasil $13 \%$ termasuk kategori baik dan kategori cukup sebesar $86 \%$. Sedangkan pada dimensi ketanggapan (responsiveness), jaminan (assurance) dan empati (empathy) secara berurutan masuk dalam kategori cukup sebesar $100 \%$, 99\%, 98\%. Hasil penelitian ini mendukung penelitian yang dilakukan oleh Setyaningrum (2015) ada hubungan yang kuat antara komunikasi terapeutik dengan kepuasan pasien. Dengan demikian semakin baik komunikasi terapeutik maka kepuasan pasien semakin tinggi, atau semakin buruk komunikasi terapeutik perawat maka kepuasan pasien semakin rendah. Kualitas pelayanan keperawatan lebih terkait dengan dimensi ketanggapan petugas untuk memenuhi kebutuhan pelayanan, kelancaran berkomuniksi antara petugas dengan pelanggan, keprihatinan, keramah tamahan petugas dalam melayani pelanggan dan kesembuhan penyakit yang diderita pasien. Ciri mutu yang baik adalah tersedia dan terjangkau, tepat kebutuhan, tepat sumber daya, tepat standar professional atau etika profesi, wajar dan aman, mutu memuaskan bagi pasien yang dilayani (Sabarguna, 2005) 
Tabel 4.Tingkat Kepuasan Pasien di Rawat Jalan Rumah Sakit JIH Yogyakarta

\begin{tabular}{cccc}
\hline Kepuasan & Kategori & $\mathbf{n}$ & $\mathbf{( \% )}$ \\
\hline Kepuasan & Baik & 1 & 1 \\
& Cukup & 87 & 87 \\
& Kurang & 12 & 12 \\
\hline Total & $\mathbf{1 0 0}$ & $\mathbf{1 0 0}$ \\
\hline &
\end{tabular}

Dari tabel 4. Hasil prosentase diperoleh hasil tingkat kepuasan pasien rawat jalan di RS JIH adalah sebesar $87 \%$ kategori sedang, $12 \%$ kategori tinggi sedangkan $1 \%$ sisanya termasuk dalam kategori rendah.

Tabel 5.Dimensi KepuasanRawat Jalan Rumah Sakit JIH Yogyakarta.

\begin{tabular}{cccc}
\hline No & Dimensi & $\mathbf{n}$ & $\mathbf{( \% )}$ \\
\hline 1. & Sikap & & \\
& Tinggi & 30 & 30 \\
& Sedang & 69 & 69 \\
2. & Rendah & 1 & 1 \\
2. & Tengetahuan & & \\
& Tinggi & 2 & 2 \\
& Sedang & 97 & 97 \\
Rendah & 1 & 1 \\
3. & Keterampilan & & \\
& Tinggi & 99 & 99 \\
& Sedang & 1 & 1 \\
Rendah & 0 & 0 \\
4 & Fasilitas & & \\
& Tinggi & 9 & 9 \\
& Sedang & 90 & 90 \\
& Rendah & 1 & 1 \\
5 & Prosedur & & \\
& Tinggi & 99 & 99 \\
& Sedang & 1 & 1 \\
& Rendah & 0 & 0 \\
\hline & Total & $\mathbf{1 0 0}$ & $\mathbf{1 0 0}$ \\
\hline
\end{tabular}

Sumber : Data primer, 2016

Dari tabel 5. tersebut di atas, diperoleh hasil penelitian pada dimensi kepuasan pasien rawat jalan di RS JIH Yogyakarta yaitu 99\% dalam kategori tinggi untuk item ketrampilan dan prosedur, sedangkan 3 item yang lain meliputi sikap, pengetahuan, dan fasilitas yang masuk dalam kategori tinggi sebesar $30 \%$, $2 \%$, dan $9 \%$. Pada kategori sedang secara berurutan dimensi pengetahuan $97 \%$, fasilitas $90 \%$, sikap 69\%, keterampilan dan prosedur 1\%.Dalam kategori rendah pada dimensi sikap, pengetahuan, fasilitas sebesar $1 \%$ dan pada dimensi keterampilan, prosedur $0 \%$. Hasil penelitian ini sesuai dengan penelitian yang dilakukan oleh Ananggadipa (2012) yang menyimpulkan bahwa ada hubungan kecemasan dengan faktor usia, jenis kelamin, faktor pengalaman pasien, faktor kondisi medis, faktor pendidikan, dan faktor akses informasi.Untuk meningkatkan mutu pelayanan keperawatan pengukuran tingkat kepuasan pasien ini mutlak diperlukan. Dengan melakukan pengukuran tingkat kepuasan, kita akan dapat mengetahui sejauh mana dimensi-dimensi mutu pelayanan yang kita berikan dapat memenuhi harapan pasien (Pohan, 2006).

\section{b. Bivariat}

Tabel 6. Tabulasi Silang Antara Tingkat Kepuasan Pasien dan Mutu Pelayanan

\begin{tabular}{|c|c|c|c|c|c|}
\hline \multirow[b]{2}{*}{$\begin{array}{c}\text { Mutu } \\
\text { pelaya } \\
\text { nan }\end{array}$} & \multirow{2}{*}{$\overline{\text { Tinggi }}$} & \multicolumn{2}{|c|}{ Kepuasan } & \multicolumn{2}{|c|}{ Nilai } \\
\hline & & Sedang & Rendah & 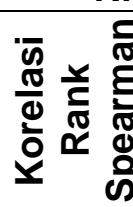 & $\begin{array}{c}\mathbf{p} \\
\text { value }\end{array}$ \\
\hline Baik & $\begin{array}{l}12(1 \\
2 \%)\end{array}$ & $33(33 \%)$ & $0(0 \%)$ & 0.440 & 0.000 \\
\hline Cukup & $\begin{array}{c}0 \\
(0 \%)\end{array}$ & 54 (54\%) & $0(0 \%)$ & & \\
\hline Kurang & $\begin{array}{c}0 \\
(0 \%)\end{array}$ & $0(0 \%)$ & $1(1.0 \%)$ & & \\
\hline
\end{tabular}

Tabel 6. Menunjukkan bahwa dari 100 responden memberikan penilaian pada variabel mutu pelayanan cukup maka tingkat kepuasan dalam kategori sedang yaitu sebanyak 54\%, sedangkan responden yang memberikan penilaian kurang pada mutu pelayanan maka tingkat kepuasan juga dalam kategori rendah, yaitu sebesar 1\%. Dalam metode korelasi Spearman Rank diperoleh nilai $\mathbf{r}$ hitung sebesar 0,440 dan probabilitas sebesar $0,000(0,000<0,05)$, maka Ha diterima 
dan Ho ditolak. Hal ini menunjukkan bahwa terdapat hubungan yang signifikan positif antara variabel mutu pelayanan dengan kepuasan pada pasien di rawat jalan Rumah Sakit JIH Yogyakarta. Hasil pengujian korelasi Spearman rank menunjukkan bahwa nilai $r$ hitung sebesar 0,440 artinya terdapat hubungan yang sedang antara mutu pelayanan dengan kepuasan

\section{KESIMPULAN DAN SARAN}

\section{A. Kesimpulan}

a. Ada hubungan yang signifikan positif antara variabel mutu pelayanan dengan kepuasan pada pasien di rawat jalan Rumah Sakit JIH Yogyakarta dengan hasil nilai $r$ hitung sebesar 0,440 dengan tingkat hubungan sedang. Artinya semakin baik mutu pelayanan maka kepuasan semakin meningkat, demikian juga sebaliknya semakin tidak baik mutu pelayanan maka kepuasan semakin menurun.

b. Mutu pelayananrawat jalan diRumah Sakit JIH Yogyakartadalam kategori cukup sebesar 54 orang (54 \%) dan kategori baik sebesar 45 orang (45\%).

c. Tingkat kepuasan pasien di rawat jalan Rumah Sakit JIH Yogyakarta dalam kategori sedang sebesar 87 orang( $87 \%$ ), sebesar 12 orang (12 $\%)$ dalam kategori tinggi.

\section{B. Saran}

\section{Bagi Manajemen Keperawatan}

Diharapkan lebih difokuskan diperhatikan mengembangkan ilmu pengetahuan dalam pemberian pelayanan keperawatan khususnya ilmu keperawatan yang berhubungan dengan keterampilan dan komunikasi perawat dalam memberikan pelayanan keperawatan dengan seminar, pelatihan bahasa Inglish, pelatihan memasang infuse, pelatihan service excellence, serta penerima karyawan yang sudah memiliki pengalaman bekerja $>$ dari 2 tahun.

2. Bagi Keperawatan Rawat Jalan Rumah Sakit JIH Yogyakarta

Penelitian ini dapat dijadikan sebagai tambahan informasi bagi perawat atas pelayanan kesehatan yang diberikan oleh perawat sehingga dapat meningkatkan kembali pelaksanaan pelayanan kesehatan agar mendorong meningkatkan kualitas pelayannan.Dengan meningkatakan kualiatas sumber daya manusia dengan menerapkan service excellence dalam pelayanan, menerapkan tindakan keperawatan sesuai SOP dan pendampingan perawat yang baru.

3. Bagi Profesi Keperawatan

Hasil penelitian ini diharapkan tenaga keperawatan dapat memperluas wawasan dan menambah ilmu terkini serta menerapkan pelayanan service excellence dengan baik, pengembangan ettitud yang baik sehingga pelayanan keperawatan tercapai pasien merasa puas dengan pelayanan

\section{DAFTAR PUSTAKA}

Depkes RI. 2009. Kategori Umur Menurut Depkes RI. http://www.scribd.com/doc/1514844 40/Kategori-Umur Menurut Depkes Rl \#scribd.Diakses pada tanggal 22 September 2015 Pukul 23.00 WIB.

Satrianegara,F., Saleha, S. 2009. Organisasi dan Manajemen

Pelayanan Kesehatan serta Kebidanan. Jakarta: Salemba Medika.

Supranto, J. 2006. Pengukuran Tingkat Kepuasan Pelanggan. Jakarta: PT. Rineka Cipta

Nursalam (Eps.3)2013. Konsep Dan Penerapan Metodologi Penelitian IImu Keperawatan. Jakarta: Salemba Medika

Sugiyono, 2009. Metode Penelitian Kuantitatif Kualitatif Dan $R \& D$. Bandung: Alfabeta. 
Sarwini W. 2014. Hubungan Mutu Pelayanan Perawat Dengan Kepuasan Pasien Rawat Inap Medikal Surginal Di RS PKU Muhammadiyah Yogyakarta.Skripsi, Program Studi IImu Keperawatan
Fakultas Kedokteran, Universitas Muhammadiyah Yogjakarta

Griffith, J. R. 2008. The Well Managed Community Hospitel. Health Administration Press, Ann Arbur, Michigan. 